\title{
Optical phantoms for biomedical polarimetry: a review
}

Joseph Chue-Sang

Mariacarla Gonzalez

Angie Pierre

Megan Laughrey

Ilyas Saytashev

Tatiana Novikova

Jessica C. Ramella-Roman 


\title{
Optical phantoms for biomedical polarimetry: a review
}

\author{
Joseph Chue-Sang, ${ }^{a}$ Mariacarla Gonzalez, ${ }^{a}$ Angie Pierre, ${ }^{a}$ Megan Laughrey, ${ }^{a}$ llyas Saytashev, ${ }^{b}$ \\ Tatiana Novikova, ${ }^{c}$ and Jessica C. Ramella-Roman ${ }^{\mathrm{a}, \mathrm{b}, *}$ \\ ${ }^{a}$ Florida International University, Department of Biomedical Engineering, Miami, Florida, United States \\ ${ }^{b}$ Florida International University, Herbert Wertheim College of Medicine, Miami, Florida, United States \\ 'LPICM Laboratoire de Physique des Interfaces et Couches Minces, CNRS, Ecole Polytechnique, Palaiseau, France
}

\begin{abstract}
Calibration, quantification, and standardization of the polarimetric instrumentation, as well as interpretation and understanding of the obtained data, require the development and use of well-calibrated phantoms and standards. We reviewed the status of tissue phantoms for a variety of applications in polarimetry; more than 500 papers are considered. We divided the phantoms into five groups according to their origin (biological/nonbiological) and fundamental polarimetric properties of retardation, depolarization, and diattenuation. We found that, while biological media are generally depolarizing, retarding, and diattenuating, only one of all the phantoms reviewed incorporated all these properties, and few considered at least combined retardation and depolarization. Samples derived from biological tissue, such as tendon and muscle, remain extremely popular to quickly ascertain a polarimetric system, but do not provide quantifiable results aside from relative direction of their principal optical axis. Microspheres suspensions are the most utilized phantoms for depolarization, and combined with theoretical models can offer true quantification of depolarization or degree of polarization. There is a real paucity of birefringent phantoms despite the retardance being one of the most interesting parameters measurable with polarization techniques. Therefore, future work should be directed at generating truly reliable and repeatable phantoms for this metric determination. Diattenuating phantoms are rare and application-specific. Given that diattenuation is considered to be low in most biological tissues, the lack of such phantoms is seen as less problematic. The heterogeneity of the phantoms reviewed points to a critical need for standardization in this field. Ultimately, all research groups involved in polarimetric studies and instruments development would benefit from sharing a limited set of standardized polarimetric phantoms, as is done earlier in the round robin investigations in ellipsometry. () The Authors. Published by SPIE under a Creative Commons Attribution 4.0 Unported License. Distribution or reproduction of this work in whole or in part requires full attribution of the original publication, including its DOI. [DOI: 10.1117/1.JBO.24.3.030901]
\end{abstract}

Keywords: polarization; scattering; anisotropy; tissue phantoms; retardation; depolarization; diattenuation.

Paper 180528VRRR received Sep. 11, 2018; accepted for publication Jan. 29, 2019; published online Mar. 8, 2019.

\section{Introduction}

The use of polarized light in clinical and preclinical applications is expanding, ${ }^{1}$ and several recent reviews by Tuchin, ${ }^{2}$ Ghosh and Vitkin, ${ }^{3}$ Qi and Elson, ${ }^{4}$ de Boer et al., ${ }^{5}$ and Baumann ${ }^{6}$ have illustrated the fast progress of this approach in the medical field.

As polarimetric techniques reach the clinical and commercial stage, there is a need to validate them with replicative systems that could serve as biological proxies and mimic the characteristic trends of typical biological observations. Over the past several decades, a variety of such systems - commonly referred to as phantoms-have been implemented for the use of general optical imaging and sensing; Pogue and Patterson ${ }^{7}$ illustrated these tools in an exhaustive review. Here, we focus uniquely on phantoms used for polarimetry in biomedicine; these phantoms were not included in previous reviews and are relevant for scientists and engineers working on polarimetric applications.

Three dominant mechanisms influence polarized light as it travels through a biological media: depolarization, retardation, and diattenuation.

Scattering is a primary contributor to the process of depolarization. Loss of polarization is mainly due to the disarrayed changes of amplitude and phase of the scattered electromagnetic field reaching a detector. ${ }^{8}$

*Address all correspondence to Jessica C. Ramella-Roman, E-mail: jramella@ fiu.edu
Scattering is generally very high in biological media due to the high density and large variety of sub- and extracellular components (such as organelles, nuclei, collagen fiber bundles, cell membrane, to name a few). Different polarization states of incident radiation-linear, circular, or elliptical-depolarize at different rates. As for the mathematical representation of depolarization, its theoretical premise is generally supported by the Mueller matrix of an intrinsic (or diagonal) depolarizer [Eq. (1a)], satisfying the covariance conditions [Eq. (1b)]: ${ }^{9}$

$$
\mathbf{M}_{\Delta}=d_{0}\left(\begin{array}{cccc}
1 & 0 & 0 & 0 \\
0 & a & 0 & 0 \\
0 & 0 & b & 0 \\
0 & 0 & 0 & c
\end{array}\right), 0<d_{0}<1,|a|,|b|,|c| \leq 1,
$$

$-a-b-c \leq 1, \quad-a+b+c \leq 1$,

$a-b+c \leq 1, a+b-c \leq 1$.

It follows from Eq. (1a) that $1-|a|$ and $1-|b|$ represent the linear depolarization power (horizontal-vertical and $\pm 45 \mathrm{deg}$ frameworks). Similarly, $1-|c|$ specifies the power of circular depolarization.

From this, the total depolarization power $\Delta$ can be calculated as 


$$
\Delta=1-\frac{|a|+|b|+|c|}{3}=1-\frac{\left|\operatorname{tr}\left(\mathbf{M}_{\Delta}\right)-1\right|}{3}, 0 \leq \Delta \leq 1 .
$$

In birefringent media, light experiences changes in propagation speeds for its different polarization components, which leads to phase differences (also called retardation) between those components. Linear retardation is the phase shift between two orthogonal linear polarization states (e.g., $0 \mathrm{deg}$ and $90 \mathrm{deg}$, or $+45 \mathrm{deg}$ and $-45 \mathrm{deg}$ ). Circular retardation (also referred to as optical rotation) is the difference in phase between the right and the left circular polarized components of light, which happens due to circular birefringence (optical activity). The Mueller matrix of a linear retarder [see Eq. (3)] depends on its phase difference parameter $\delta$ and on the azimuth $\theta$ of its fast axis:

$$
R=\left(\begin{array}{cccc}
1 & 0 & 0 & 0 \\
0 & \cos ^{2}(2 \theta)+\sin ^{2}(2 \theta) \cos \delta & \sin 2 \theta \cos 2 \theta(1-\cos \delta) & -\sin 2 \theta \sin \delta \\
0 & \sin 2 \theta \cos 2 \theta(1-\cos \delta) & \sin ^{2}(2 \theta)+\cos ^{2}(2 \theta) \cos \delta & \cos 2 \theta \sin \delta \\
0 & \sin 2 \theta \sin \delta & -\cos 2 \theta \sin \delta & \cos \delta
\end{array}\right)
$$

The retardation $(\delta)$ property of a uniaxial medium is frequently expressed through its birefringence and can be written as shown in Eq. (4), where $n_{e}$ and $n_{o}$ are extraordinary and ordinary refractive indices of a birefringent material, respectively, $d$ is the distance traveled by light (wavelength $\lambda_{0}$ ) through the birefringent medium, $\Delta n=n(\theta)-n_{o}$, where $n(\theta)$ is the refractive index seen by the photon propagating in the direction $\mathbf{u}\left(u_{x}, u_{y}, u_{z}\right)$. Angle $\theta$ is the angle between the direction $\mathbf{u}$ and extraordinary axis of birefringent material defined as $\boldsymbol{e}(\cos \eta, \sin \eta, 0)$ :

$$
\begin{aligned}
& \delta=\frac{2 \pi d \Delta n}{\lambda}, \\
& n(\theta)=\frac{n_{o} n_{e}}{\left(n_{e}^{2} \cos ^{2} \theta+n_{o}^{2} \sin ^{2} \theta\right)^{0.5}}, \\
& \theta=\cos ^{-1}\left[\frac{u_{x} \cos \eta+u_{y} \sin \eta}{\left(u_{x}^{2}+u_{y}^{2}+u_{z}^{2}\right)^{0.5}}\right] .
\end{aligned}
$$

Birefringence itself can be divided into "intrinsic birefringence" and "form birefringence.", Typically, biological tissues rich in extracellular matrix (ECM) fibers, for example, skin, cornea, sclera, tendon, uterine cervix, and cardiac tissue, exhibit retardation.

Mueller matrix polarimetry ${ }^{2-4}$ and polarization-sensitive optical coherence tomography (PS-OCT) ${ }^{10}$ are techniques capable of quantifying many of the aforementioned parameters of interest. Calculation of the Mueller matrix requires the modulation of both light source and detector into a minimum of four different polarization states for a total of 16 measurements. Once the Mueller matrix is determined, it can be decomposed ${ }^{11}$ as a sequence of elementary polarization components: a diattenuator, a retarder, and a depolarizer. PS-OCT is an extension of OCT, a technique based on low-coherence interferometry that can provide high-resolution cross-sectional imaging of biological tissue, and it too can be used to quantify birefringence, diattenuation, and depolarization index, a parameter related to depolarization.

Diattenuation, also called dichroism, is generally considered to have the smallest impact on polarized light propagating in biological media. Diattenuation arises from polarizationselective attenuation of the electrical field. Related to diattenuation is the property of optical activity, also known as circular birefringence, which is characterized by the rotation of the polarization plane of linearly polarized light about the axis of propagation. ${ }^{2}$ This property is prevalent for chiral molecules such as glucose, proteins, and nucleic acids. ${ }^{3}$
The use of polarimetry in monitoring biological tissue often focuses on quantification of the tissue preferential azimuth (i.e., the orientation of optical axis of uniaxial birefringent medium) related to the arrangement of a collagenous ECM or other cellular assembly. Skeletal muscle and cardiac tissue are both strongly depolarizing and birefringent due to cellular components and layered structure.

Collagen, animal cornea, retina, and optic nerves have all been shown to have large birefringence and preferential alignment through PS-OCT and polarized light microscopy. ${ }^{12-14}$ Several studies using PS-OCT imaging on articular cartilage, which is rich in oriented collagen fibers, have shown changes in collagen retardation in depth. ${ }^{15-18}$ Nerves have also been shown to yield retardation with polarization-sensitive spectroscopy. ${ }^{19}$ Since birefringence is the most common source of retardation and signal for this modality, in general most retardance phantoms can be used as PS-OCT phantoms.

Microtubules made from extracted elements of the porcine brain and axonemes prepared from sea urchin have been examined using polarized light microscopy, where fibers can be visualized. $^{20}$ The ECM of the cervix is composed of about $70 \%$ collagen and, therefore, has shown to have a significant retardation. Chue-Sang et al. ${ }^{21}$ used Mueller matrix polarimetry to calculate retardance, depolarization, and collagen fiber azimuth of ex vivo porcine cervix samples (seen in Fig. 1). Pierangelo et al. used wide-field multiwavelength Mueller matrix polarimeters to image cervical neoplasia and colon cancer. ${ }^{22-30}$

Vitkin et al. used Mueller polarimetry to determine the local structural disorders of the bladder ${ }^{31}$ and myocardium. ${ }^{32}$ Enhancement of superficial structure by eliminating deep penetrating scattered photons is also a common use of polarimetry in medicine. Groner et al. ${ }^{33}$ used cross-polarization to highlight superficial vascular contrast in intravital microscopy, applying this technique, among others, to study brain perfusion and pancreatic and hepatic microcirculation. ${ }^{33-38}$

Polarized light imaging has been used extensively to enhance surface contrast for dermatologic applications. ${ }^{39}$ Demarcation of margins of skin cancers, not visible to the naked eye, has been conducted by several researchers, starting with setups focusing on linear depolarization to other systems, ${ }^{40-43}$ utilizing full Stokes vector polarimetry and out-of-plane approaches. ${ }^{44-46}$ The skin stratum corneum has been shown to be highly scattering hence producing strong depolarization. ${ }^{47,48}$ Changes in retardation have been associated with the presence of collagen in the dermis. For this reason, scars have a strong response to polarized light as collagen in wounds recombines in the direction of local forces. ${ }^{46}$ 

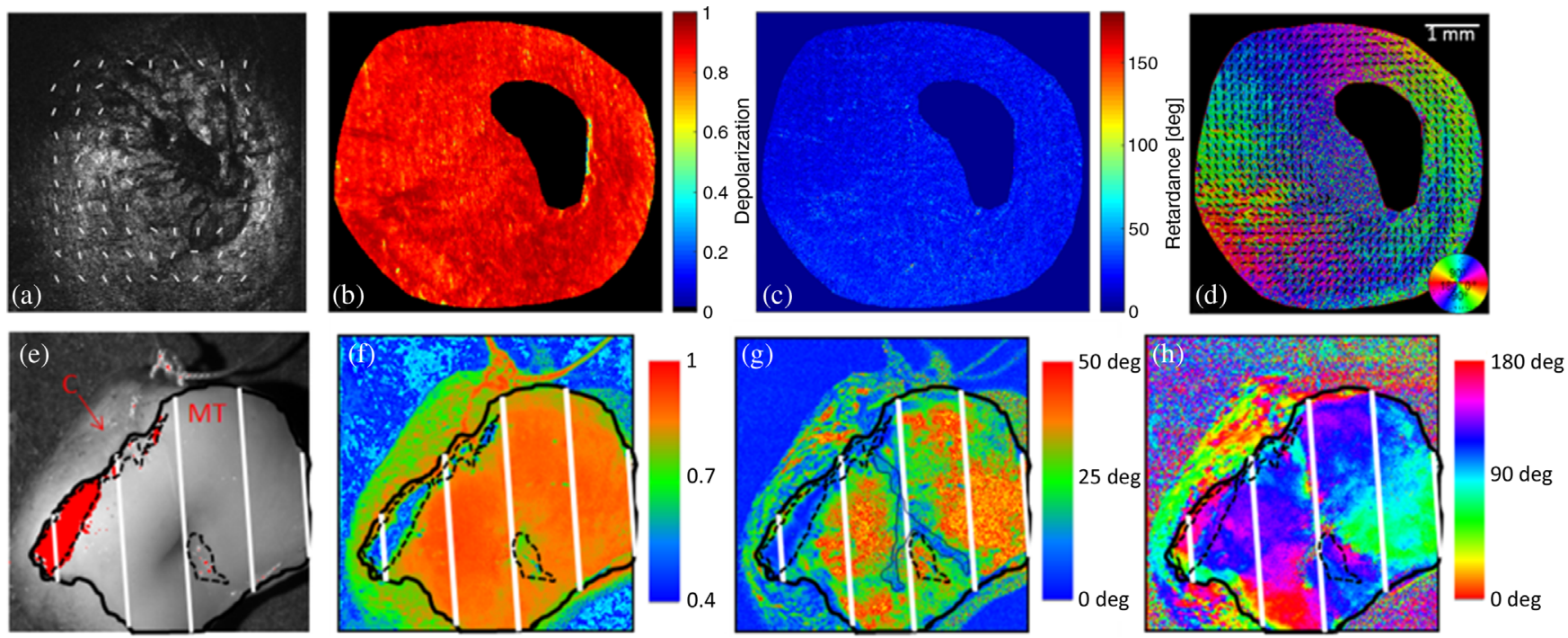

Fig. 1 Mueller matrix-derived parameters (Lu-Chipman decomposition ${ }^{11}$ ) of an ex vivo porcine cervix: (a) CCD image, (b) depolarization power, (c) scalar retardation, and (d) azimuth of optical axis. Darkened area in the center of the image is the cervical OS. Overlaid lines are calculated from the mean of subsections of the azimuth depicted by the false color. ${ }^{21}$ Mueller matrix-derived parameters (Lu-Chipman decomposition) of healthy human cervical specimen: (e) CCD image, (f) depolarization power, (g) scalar retardation, and $(\mathrm{h})$ azimuth of optical axis. ${ }^{22}$

\section{Optical Phantoms}

We have categorized all phantoms by their dominant polarization property-namely, depolarization, retardation, diattenuation, or optical activity. We have also introduced a separate table for biological tissues used as phantoms. Many phantoms exhibit more than one property; hence, they may appear in more than one table, these repeated phantoms are identified by an asterisk (*). The retardation phantoms table includes an induced retardation column. This column is included to differentiate phantoms which are inherently birefringent due to their structure from phantoms that are mechanically stressed, strained, or otherwise manipulated in order to change their birefringence. Many of the phantoms cited in this review have been used by the same investigators in multiple journals, for simplicity, we have not cited all the articles using the same phantoms and limited the review to the ones that were substantially different to each other.

\subsection{Biological Phantoms}

The construction of polarimetric phantoms is a complex process; hence, biological samples are commonly used in polarization-sensitive optical modalities (Table 1). Collagen-rich tissues, for example, tendons or rat tails, are the most commonly used in polarimetry. As most biological tissues, collagen scatters (and, consequently, depolarizes); more importantly, collagen introduces a phase shift between orthogonal polarization states of incident polarized light ${ }^{2}$ due to its strong birefringence. Since many healthy collagen-rich tissues behave as uniaxial birefringent media, the azimuth of optical axis of linear retardation related to collagen alignment can often be measured. ${ }^{21,22,27,51,59,77,78}$

Chicken or cow tendons have been used by many groups $^{45,50,60,73-76}$ to validate polarization-based optical instruments. Azimuth angle is calculated ${ }^{45,50,58,60,72-76,79-83}$ as well as an increase in scalar retardance due to birefringence. Similar to tendon, murine tails also contain collagen fibers which are strongly aligned. Since the azimuth of the collagen fibers preferential orientation can be directly observed, a typical validation test for polarimeters includes positioning a tendon or rat tail at predetermined angles and then measuring samples at different and well-known angular positions..$^{21,59,72}$

While muscle tissue can be used for the same purposes as collagen-based phantoms, the interpretation of the results is less straightforward due to the increased cellularity of these tissues. $^{61}$ Studies of myocardium muscle ${ }^{32,40,50,54-56,64,66-68}$ have been conducted by several investigators showing loss of retardation and local order for infarcted tissue. For this reason, samples of myocardium have been used to validate different polarimetric systems. Ghosh et al. ${ }^{57}$ used Mueller matrix decomposition to calculate depolarization, diattenuation, and retardance of fixed rat myocardial tissue.

Heart valve leaflets are another highly collagenous and anisotropic tissue that have been used as a depolarization and retardation phantom. ${ }^{60}$ As in previous example, the azimuth of collagen fibers' preferential orientation can be detected and used for instrument characterization. Changes in depolarization can also be observed by treating the sample with collagenase. ${ }^{58,59}$

Artificial skin models grown from epidermal keratinocytes forming a multilayered epidermis on top of collagen I hydrogel with dermal fibroblasts have also been used to mimic the interaction of polarized light with the skin. ${ }^{71}$ Unstained cuts of fixed skin equivalents of varying thickness (range: 5 to $30 \mu \mathrm{m}$ ) were measured in transmission with Mueller microscopy and the values of retardation and depolarization parameters were extracted using logarithmic decomposition ${ }^{84}$ of the measured Mueller matrices. The measurements confirmed parabolic dependence of depolarization and linear dependence of retardation on thickness, as follows from differential Mueller matrix formalism. 
Table 1 Biological tissues used as polarization phantoms.

\begin{tabular}{|c|c|c|c|c|}
\hline Tissue type & Preparation & Polarization property & $\begin{array}{l}\text { Transmission/ } \\
\text { reflectance }\end{array}$ & Ref. \\
\hline Axonemes (sea urchin) & $\begin{array}{l}\text { Extraction from sea urchin sperm and } \\
\text { purification steps }\end{array}$ & Retardation & $\mathrm{R}$ & 20 \\
\hline Bladder (porcine) & Excised, fresh & $\begin{array}{l}\text { Depolarization, retardation, } \\
\text { diattenuation }\end{array}$ & $\mathrm{R}$ & 49 \\
\hline Brain (porcine) & Phosphate-buffered saline solution (0.02 M) & Depolarization & $\mathrm{R}$ & 50 \\
\hline Cartilage (animal) & Excised, fresh & Depolarization, retardation & $\mathrm{R}$ & $15-18$ \\
\hline Cartilage (porcine) & Excised, fresh & $\begin{array}{l}\text { Retardation, depolarization, } \\
\text { diattenuation }\end{array}$ & $\mathrm{T}$ & 18 \\
\hline Cervix (porcine) & $\begin{array}{l}\text { Fixed in } 4 \% \text { paraformaldehyde and } \\
\text { embedded in paraffin }\end{array}$ & Depolarization, retardation & $\mathrm{R}$ & 51 \\
\hline Eye (cornea) & Excised, fresh & Retardation & $\mathrm{R}$ & 13 and 14 \\
\hline Eye (optic nerve) & Cryosectioned & Retardation & $\mathrm{R}$ & 12 \\
\hline Eye (retina) & Excised, fresh & Retardation & $\mathrm{R}$ & 14 \\
\hline Fibroblast (rat) & Suspension & Depolarization & $\mathrm{R}$ & 52 and 53 \\
\hline Heart (myocardium) & Excised, fixed & Depolarization, retardation & $\mathrm{R}$ & $32,54,55$, and 56 \\
\hline Heart (porcine myocardium) & Phosphate-buffered saline solution (0.02 M) & Depolarization & $\mathrm{R}$ & 50 \\
\hline Heart (rat myocardium) & $10 \%$ formalin and cut into $1 \mathrm{~mm}$ slices & $\begin{array}{l}\text { Retardation, diattenuation, } \\
\text { depolarization }\end{array}$ & $\mathrm{R}$ & 57 \\
\hline Heart (valve leaflet) & Excised, fresh & Depolarization, retardation & $\mathrm{R}$ & 58 and 59 \\
\hline Heart (porcine valve) & Excised, fresh & Retardation & $\mathrm{R}$ & 60 and 58 \\
\hline Heart (porcine aorta) & Excised, fresh & Retardation & $\mathrm{R}$ & 61 \\
\hline Heart (bovine right ventricle) & Cut into $2 \mathrm{~cm} \times 2 \mathrm{~cm} \times 1 \mathrm{~cm}$ sections & Retardation, diattenuation & $\mathrm{R}$ & 62 \\
\hline Heart (swine right ventricle) & Excised, fresh & Retardation & $\mathrm{R}$ & 63 \\
\hline $\begin{array}{l}\text { Heart (rabbit right } \\
\text { ventricular wall) }\end{array}$ & $\begin{array}{l}3.7 \% \text { formaldehyde for } 1 \text { day and } 20 \% \\
\text { sucrose solution for an additional } 2 \text { days }\end{array}$ & Retardation & $\mathrm{R}$ & 64 \\
\hline Kidney cortex & Phosphate-buffered saline solution (0.02 M) & Depolarization & $\mathrm{R}$ & 50 \\
\hline Liver & Phosphate-buffered saline solution (0.02 M) & Depolarization & $\mathrm{R}$ & 40 and 50 \\
\hline Melanin granules & Suspension & Depolarization, retardation & $\mathrm{R}$ & 65 \\
\hline Microtubules & $\begin{array}{l}\text { Extraction from porcine brain and } \\
\text { purification steps }\end{array}$ & Retardation & $\mathrm{R}$ & 20 \\
\hline Nerve (lobster leg) & Excised, fresh & Depolarization, retardation & $\mathrm{R}$ & 19 \\
\hline Skeletal muscle & Excised, fresh & Depolarization, retardation & $\mathrm{R}$ & $\begin{array}{l}32,40,50,54-56 \\
64 \text {, and } 66-68\end{array}$ \\
\hline Skin & In vivo & Depolarization, retardation & $\mathrm{R}$ & 47,48 , and 69 \\
\hline Skin (calf) & Excised, fresh & Retardation & $\mathrm{T}$ & 70 \\
\hline Skin equivalent model & Fixed and cut into few $\mu \mathrm{m}$ slices & Depolarization, retardation & $\mathrm{T}$ & 71 \\
\hline Tail (rat) & Frozen and thawed & Depolarization, retardation & $\mathrm{R}$ & 72 \\
\hline Tendon & Excised, fresh & Depolarization, retardation & $\mathrm{R}$ & $\begin{array}{l}45,50,60 \\
\text { and } 73-76\end{array}$ \\
\hline Yeast cells & Suspension & Depolarization & $\mathrm{R}$ & 53 \\
\hline
\end{tabular}




\subsection{Depolarizing Phantoms}

Several authors have studied the effect of particle size, density, and index of refraction on the polarization of scattered light. ${ }^{85,86}$ As suggested by the results of these studies, the main scatterers in biological tissues are nuclei, organelles, and bulk tissue structures that limit the photon penetration depth and depolarize light traveling through these media. ${ }^{53}$ The cell nuclei and organelles are frequently modeled as spherical scattering particles ${ }^{87}$ of refractive index varying between 1.33 and 1.47. The components of ECM, such as collagen and elastin, have been repre-

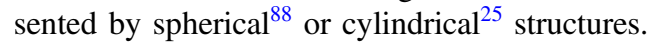

Work by MacKintosh et al. ${ }^{89}$ showed that circular polarization was maintained for longer depths as compared to linearly polarized light in Mie scattering regime (scatterer size $\geq$ light wavelength in the medium). In one of the relevant studies,
Monte Carlo simulations supported this finding by showing that mean penetration depth was $\sim 2$ mean free paths (MFP) for linearly and 10 MFP for circularly polarized light in Mie scattering regime. ${ }^{86}$

Suspensions of microspheres and other small particles are commonly used to create phantoms with scattering properties (Table 2). The amount of scattering can be adjusted depending on the size and concentration of the microspheres based on the Mie scattering theory. On a smaller scale, nanoparticles have also been widely used to create scattering phantoms in Rayleigh scattering regime. These particles can also be embedded in solid host media, such as gels or polymers, to ensure scattering properties of those materials. In addition, India ink, hemoglobin, and dyes are commonly added to influence the absorbing characteristics.

Several studies, such as Antonelli, Rakovic et al., and Cote and Vitkin, ${ }^{75,94,95}$ have used aqueous polystyrene microsphere

Table 2 Depolarizing phantoms. *Phantoms that were also tested for other polarization properties in corresponding reference paper.

\begin{tabular}{|c|c|c|c|c|c|}
\hline Depolarizing agent & Embedding material & Tissue mimicking & $\begin{array}{l}\text { Phantom } \\
\text { thickness }\end{array}$ & $\begin{array}{l}\text { Transmission/ } \\
\text { reflectance }\end{array}$ & Ref. \\
\hline GNPs $(50 \mathrm{~nm})$ & Intralipid & Contrast agent & Semi-infinite & $\mathrm{R}$ & 90 \\
\hline Intralipid* & Water, India ink & Bladder wall & Semi-infinite & $\mathrm{R}$ & 49 \\
\hline Intralipid & Water & Turbid biological media & Semi-infinite & $\mathrm{R}$ & $\begin{array}{l}53,69 \\
\text { and } 91\end{array}$ \\
\hline Intralipid or polystyrene microspheres & Water, Naphthol green & Porcine liver & $1 \mu \mathrm{m}, 1.4 \mu \mathrm{m}$ & $\mathrm{R}$ & 92 \\
\hline Kapton tape (stacked)* & Layered against a rigid base & Theoretical standard & Semi-infinite & $\mathrm{R}$ & 93 \\
\hline $\begin{array}{l}\text { Mylar (biaxially oriented polyethylene } \\
\text { terephthalate) }^{\star}\end{array}$ & Laid against a plexiglass base & Theoretical standard & Semi-infinite & $\mathrm{R}$ & 93 \\
\hline Polystyrene microspheres & Water & Turbid biological media & Semi-infinite & $\mathrm{R}$ & $\begin{array}{l}24,40,53 \\
\text { and } 94-97\end{array}$ \\
\hline Polystyrene microspheres & Intralipid & Turbid biological media & Semi-infinite & $\mathrm{R}$ & 53 and 2 \\
\hline Polystyrene microspheres & Polyacrylamide, sucrose & Turbid biological media & $1 \mathrm{~cm}^{3}$ & $\mathrm{~T}$ & 3 \\
\hline $\begin{array}{l}\text { Polystyrene microspheres }(0.5 \mu \mathrm{m}) \\
\text { and fiber glass* }\end{array}$ & Polyacrylamide & Anisotropic sample & $1 \times 2 \times 4 \mathrm{~cm}^{3}$ & $\mathrm{~T}$ & 98 \\
\hline $\begin{array}{l}\text { Polystyrene microspheres and } \\
\text { silk fibers }^{\star}\end{array}$ & Water & Anisotropic sample & $2.1 \mathrm{~cm}$ & $\mathrm{R}$ & 88 and 99 \\
\hline Quartz plate (wedged)* & None & $\mathrm{N} / \mathrm{A}$ & $3 \mathrm{~mm}$ & $\mathrm{~T}$ & 100 \\
\hline Melanin granules* & Water & $\begin{array}{c}\text { Retina/retinal pigment } \\
\text { epithelium }\end{array}$ & Semi-infinite & $\mathrm{R}$ & 65 \\
\hline Silicon phantom (extruded) & Air between layers & Anisotropic sample & $2 \mathrm{~mm}$ & $\mathrm{R}$ & 51 \\
\hline Silicon (amorphous) ${ }^{*}$ & None & $\begin{array}{l}\text { Theoretical polarization } \\
\text { standard }\end{array}$ & Semi-infinite & $\mathrm{R}$ & 93 \\
\hline Silicon (poly-) $)^{*}$ & None & Theoretical standard & Semi-infinite & $\mathrm{R}$ & 93 \\
\hline Silicon grating & Silicon wafer & Theoretical standard & Semi-infinite & $\mathrm{R}$ & 101 \\
\hline $\mathrm{TiO}_{2}$ nanoparticles $(530 \mathrm{~nm})$ & PVC-based transparent material & Biopsy samples & $1 \mathrm{~mm}$ & $\mathrm{~T}$ & 23 \\
\hline $\mathrm{TiO}_{2}$ & Wax & Skin & 2 and $5 \mathrm{~mm}$ & $\mathrm{R}$ & 44 \\
\hline ZnO nanoparticles (340 nm) & PVCP stock solution & Human skin & 0.2 -to $2 \mathrm{~mm}$ & $\mathrm{~T}$ & 102 and 103 \\
\hline
\end{tabular}


(a)

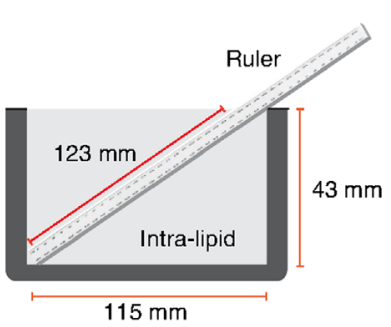

(b)

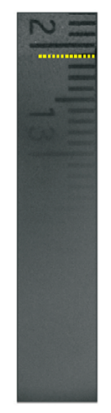

(c)

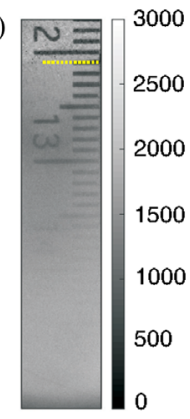

Fig. 2 Image from Ref. 69. (a) Ruler placed obliquely in a tank containing Intralipid ${ }^{\circledR}$ solution, (b) elliptical channel image at 45 deg after subtraction method 1, (c) elliptical channel image at 45 deg after subtraction method 2. (b) and (c) have a common colorbar represented at the right edge of the figure. Yellow-dotted line represents the Intralipid ${ }^{\circledR}$-air interface. Each graduation on the ruler (i.e., $1 \mathrm{~mm}$ ) corresponds to $0.35 \mathrm{~mm}$ in actual depth. Wavelength: $633 \mathrm{~nm}$. Text is from Ref. 69.

suspensions as backscattering polarization phantoms. In order to measure the change in scattering (i.e., depolarization power) calculated for different suspensions, microsphere diameter was varied. ${ }^{24,40,53,94-96}$ This class of phantoms has also been shown to depolarize linear polarization less with smaller-diameter microspheres as compared to circular polarization, while, with an increase of the microsphere diameter, circular polarization has been reported to be better preserved as compared to linear polarization. ${ }^{96}$

While purely aqueous monodispersed suspensions of microspheres are most commonly used in scattering experiments, intralipid has also been used to create depolarizing phantoms. ${ }^{2,53}$ Intralipid is commonly used as a nutrition supplement and is an emulsion of fatty micelles; therefore, scattering is due to multidispersed spherical structures. Aqueous intralipid suspensions with different dilution factors starting at 1:500 to 1:1 have been used to test depolarization with reflectance polarimetry. ${ }^{53,69,91}$ An example of such experiment can be seen in Fig. 2, where loss of elliptical polarization is measured as a function of depth in an intralipid suspension as reported by Sridhar and Da Silva. ${ }^{69}$ While intralipid suspension exhibits monotonic dependence of depolarization on light wavelength, the use of gold nanoparticles (GNPs) suspended in intralipid creates more complicated depolarization behavior. ${ }^{90}$

Titanium dioxide $\left(\mathrm{TiO}_{2}\right)$ is another material commonly used to produce scattering in optical phantoms. $\mathrm{TiO}_{2}$ particles have been used in solid host media, such as polydimethylsiloxane or polyurethane, where, before the curing process, these particles

are mixed into the polymer. Adjusting the concentration of $\mathrm{TiO}_{2}$ particles makes it possible to change the amount of depolarization., ${ }^{7,23}$ Zinc oxide $(\mathrm{ZnO})$ particles are also commonly mixed into polymers. ${ }^{102,103}$ Melanin suspensions of rising concentrations can be used to test depolarization with PS-OCT and model the same phenomenon in the retinal pigmented epithelium. As demonstrated by Baumann et al., ${ }^{65}$ the change in depolarization based on melanin concentration has a linear relationship with degree of polarization uniformity (DOPU).

\subsection{Retarding Phantoms}

Polymer-based materials are a common source of retardation. Due to their molecular structure or preparation process, many polymers possess intrinsic birefringence (i.e., behave as uniaxial crystals). ${ }^{104}$ Others can be induced to become birefringent by applying mechanical stress to the material. ${ }^{3,105}$ Many of these polymers are transparent; hence, scattering particles such as microspheres can be added to better simulate biological media. Electrospun polymer fibers, fabricated by charging droplets of polymer at high voltages which creates an interconnected network of small fibers, ${ }^{106}$ were used by Goth et al. ${ }^{60}$ to determine the degree of anisotropy of the overall structure. The anisotropic biological elements in the ECM (particularly collagen and elastin) have been simulated with several materials, including silk $^{88,99}$ and glass fibers. ${ }^{98,107}$ An example of fibrous phantom is shown in Fig. 3. Here, the phantom is composed of polystyrene microspheres and well-aligned glass fibers embedded in polyacrylamide (glass fibers have a $10-\mu \mathrm{m}$ diameter and 1.547 refractive index).

Phantoms for PS-OCT require a strong backscattering to generate a high image contrast and have ideally well-defined layers with homogeneous yet different values of birefringence (Table 3). Accordingly, Liu et al. have used a phantom consisting of a long birefringent polymer band laid over four smaller bands of differing birefringence. The optical axes of bottom four bands were oriented at $45 \mathrm{deg}$ with the optical axis of top layer allowing for a depth-dependent change in retardation. ${ }^{108}$ An example of this retarding phantom is shown in Fig. 4.

Ghosh et al. induced changes in retardation by stretching a polyacrylamide phantom. Moreover, changing birefringence, and mixing polystyrene microspheres and sucrose into the polymer, produced phantoms that could be used to characterize retardance, depolarization, and diattenuation., ${ }^{3,98,109}$ Extruded silicon, silicon wafers with gratings, and other types of silicon (poly and amorphous), as well as different tapes (e.g., Kapton and Mylar) normally used in solar panels, have been used to create phantoms containing different combinations of

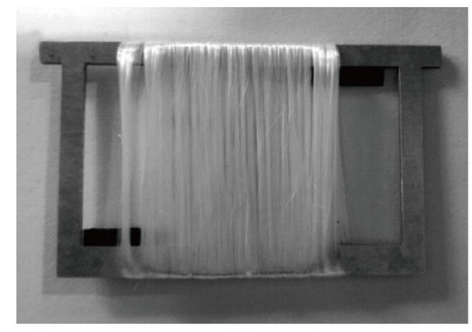

(a)

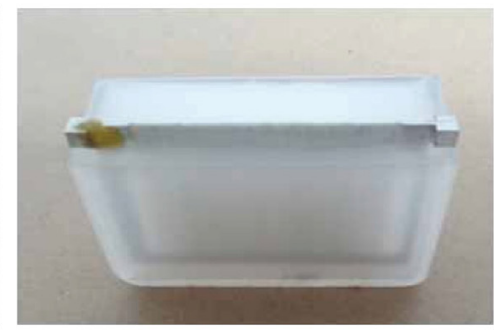

(b)

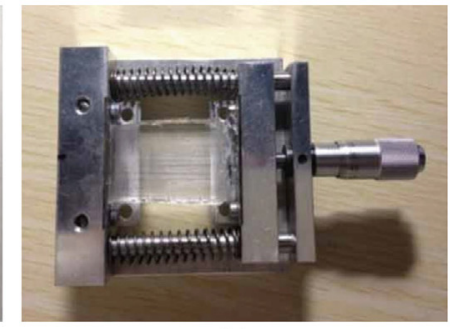

(c)

Fig. 3 Image from Ref. 107. (a) Cylinder model, (b) sphere-cylinder model, and (c) sphere-cylinder birefringence model. 
Table 3 Retardation phantoms. The "induced retardation" column is for differentiating between phantoms which inherently exhibit their birefringence due to their structure and phantoms that are mechanically stressed, strained, or otherwise manipulated in order to change their birefringence. *Phantoms that were also tested for other polarization properties in corresponding reference paper.

\begin{tabular}{|c|c|c|c|c|c|c|}
\hline Retardation material & Embedded material & Induced retardation & Tissue mimicking & $\begin{array}{l}\text { Phantom } \\
\text { thickness }\end{array}$ & $\begin{array}{l}\text { Transmission/ } \\
\text { reflectance }\end{array}$ & Ref. \\
\hline Birefringent film & Intralipid, India ink & Structure & ECM & Semi-infinite & $\mathrm{R}$ & 49 \\
\hline $\begin{array}{l}\text { Electrospun fibers } \\
(0.6 \text { to } 1.0 \mu \mathrm{m})\end{array}$ & None & Structure & Heart valve leaflet & Semi-infinite & $\mathrm{R}$ & 60 \\
\hline Human hair & None & Structure & Human hair & $\mathrm{N} / \mathrm{A}$ & $\mathrm{R}$ & 15 \\
\hline Kapton tape (stacked) & $\begin{array}{l}\text { Layered against } \\
\text { a rigid base }\end{array}$ & Structure (layers) & Theoretical standard & Semi-infinite & $\mathrm{R}$ & 93 \\
\hline $\begin{array}{l}\text { Mylar (biaxially } \\
\text { oriented polyethylene } \\
\text { terephthalate) }\end{array}$ & $\begin{array}{c}\text { Laid against } \\
\text { a plexiglass base }\end{array}$ & Structure & Theoretical standard & Semi-infinite & $\mathrm{R}$ & 93 \\
\hline Plastic cap* & None & Structure & Theoretical standard & Semi-infinite & $\mathrm{R}$ & 76 \\
\hline Polycarbonate & None & $\begin{array}{l}\text { Longitudinal stretch } \\
\text { (heating and cooling) }\end{array}$ & Turbid biological tissue & $250 \mu \mathrm{m}$ & $\mathrm{R}$ & 108 \\
\hline $\begin{array}{l}\text { Polyacrylamide } \\
\text { polymer (elastic) }\end{array}$ & None & $4 \mathrm{~mm}$ stretch & Turbid biological tissue & $4 \mathrm{~mm}$ & $\mathrm{R}$ & 109 \\
\hline Polyacrylamide gels & $\begin{array}{l}\text { Polystyrene microspheres, } \\
1 \mathrm{M} \text { sucrose }\end{array}$ & Stretching & Turbid biological tissue & $1 \times 1 \times 4 \mathrm{~cm}^{3}$ & $\mathrm{~T}$ & 105 \\
\hline Polyacrylamide* & $\begin{array}{l}\text { Sucrose, polystyrene } \\
\text { microspheres }\end{array}$ & Stretching & Turbid biological tissue & $1 \times 1 \times 1 \mathrm{~cm}^{3}$ & $\mathrm{~T}$ & 3 \\
\hline Polyacrylamide* & $\begin{array}{c}\text { Polystyrene } \\
\text { microspheres and } \\
\text { well-aligned fiber glass }\end{array}$ & $\begin{array}{l}\text { Stretching ( } 1 \text { to } 5 \mathrm{~mm}) \text {, } \\
\text { birefringence }=0 \text { to } 10^{-5}\end{array}$ & Turbid biological tissue & $1 \times 2 \times 4 \mathrm{~cm}^{3}$ & $\mathrm{~T}$ & $\begin{array}{c}98 \text { and } \\
107\end{array}$ \\
\hline $\begin{array}{l}\text { Polyethylene (low } \\
\text { density) }\end{array}$ & None & Bending (up to $2.5 \mathrm{MPa}$ ) & Turbid biological tissue & $1 \mathrm{~mm}$ & $\mathrm{R}$ & 110 \\
\hline Polystyrene sphere & None & Structure & Infarcted myocardium & $8 \mathrm{~mm}$ diameter & $\mathrm{T}$ & 111 \\
\hline $\begin{array}{l}\text { Polystyrene } \\
\text { microspheres }\end{array}$ & Water & Structure & Turbid biological media & Semi-infinite & $\mathrm{R}$ & $\begin{array}{l}75,97 \\
112\end{array}$ \\
\hline Polyurethane & $\begin{array}{l}\text { Particle filled } \\
\text { polypropylene }\end{array}$ & Longitudinal stretch & Theoretical standard & $1 \mathrm{~mm}$ & $\mathrm{R}$ & 113 \\
\hline Silicon (extruded) & Air between layers & Structure & Theoretical standard & $2 \mathrm{~mm}$ & $\mathrm{R}$ & 51 \\
\hline Silicon (amorphous) & None & Structure & Theoretical standard & Semi-infinite & $\mathrm{R}$ & 93 \\
\hline Silicon (poly-) & None & Structure & Theoretical standard & Semi-infinite & $\mathrm{R}$ & 93 \\
\hline Silk fibers* & Water & Structure & Anisotropic sample & Semi-infinite & $\mathrm{R}$ & $\begin{array}{l}88 \text { and } \\
99\end{array}$ \\
\hline
\end{tabular}

diattenuation, depolarization, and retardation properties. ${ }^{51,93,101}$ Figure 5 shows an example of an experimental setup used to induce birefringence in a polymer through mechanical strain by Wood et al. ${ }^{114}$

In order to account for different geometries and extract geometry-independent metrics of anisotropy, retardance measurements have been taken using an 8-mm-diameter polystyrene sphere of known anisotropy axis azimuth. ${ }^{111}$ Fan et al. ${ }^{76}$ imaged a plastic cap to determine its retardation with PS-OCT.

\subsection{Diattenuating Phantoms}

The asymmetry of a molecule can result in selective transmission of an incident state of polarized light. Swami et al. ${ }^{115}$ measured diattenuation as a parameter to identify the general shape of GNPs (Table 4). Differently shaped GNPs displayed different spectroscopic diattenuation values. Chen et al. ${ }^{116}$ and Lung et al. ${ }^{117}$ used a quarter-wave plate and a polarizer to test the performance of an analytical model for low 

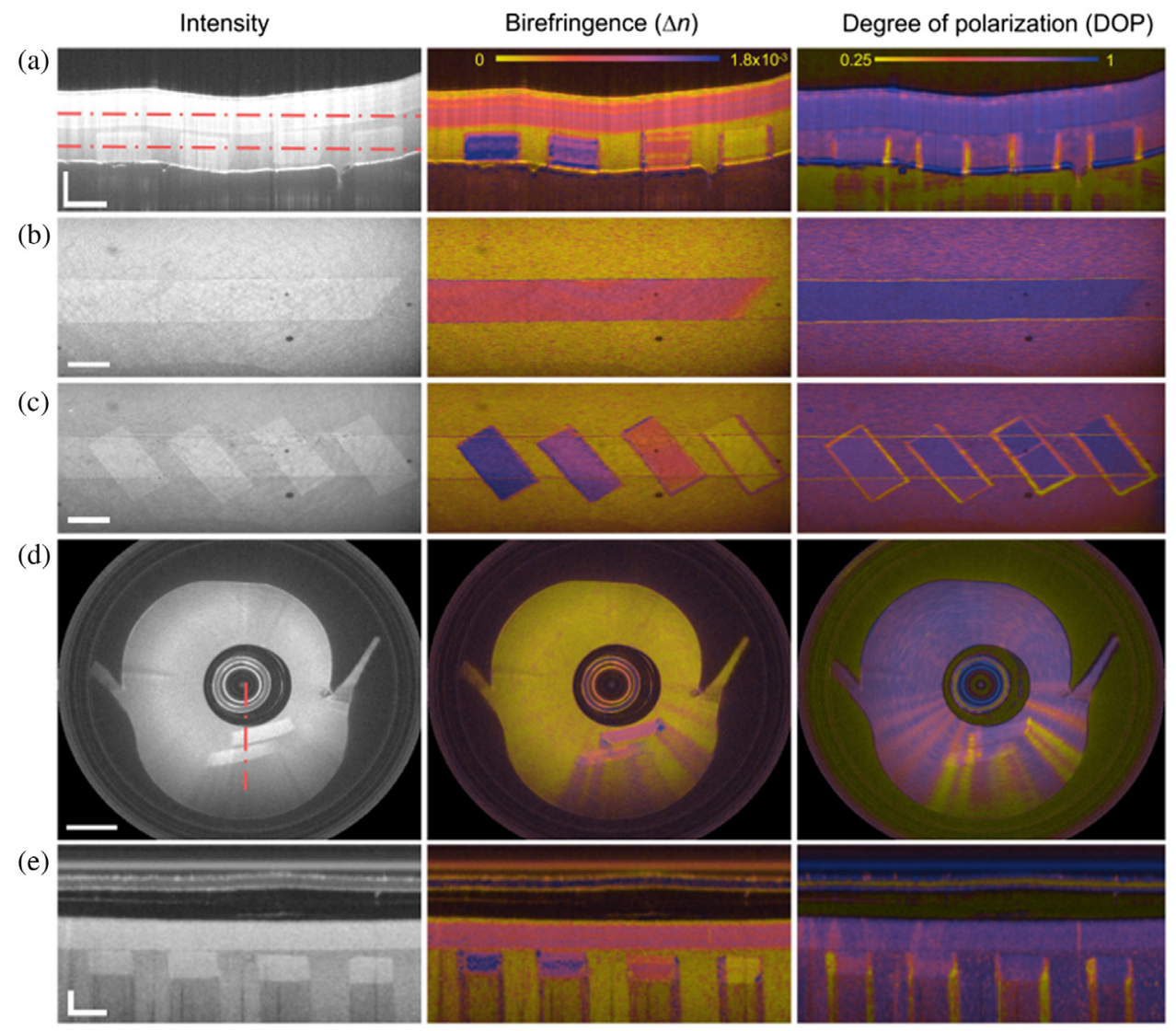

Fig. 4 Image from Ref. 108. (a)-(c) Intensity, birefringence, and DOP images of the slab and (d and e) cylindrical phantoms. (a) Representative cross-sectional images of the birefringence phantom for galvanometer-scanning system. (b) and (c) En-face images at different depths as indicated by the dashed red lines in (a). Horizontal and vertical scale bars for (a)-(c): $2 \mathrm{~mm}$ and $250 \mu \mathrm{m}$, respectively. (d) Representative images obtained from one rotational scan with the catheter. Scale bar: $1 \mathrm{~mm}$. (e) Longitudinal sections obtained from a pull-back data set, with its corresponding location indicated by the dashed red line in (d). Radial and horizontal scale bars: $250 \mu \mathrm{m}$ and $1 \mathrm{~mm}$, respectively. (Text from Ref. 108.)

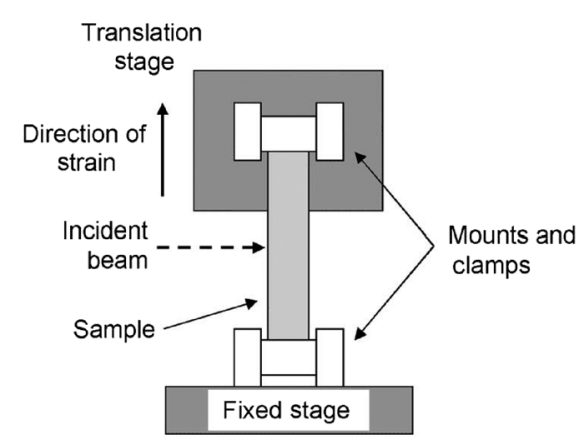

Fig. 5 Image from Ref. 114. Apparatus to create birefringent phantoms.

diattenuating optical components as they were rotated from $0 \mathrm{deg}$ to $150 \mathrm{deg}$ with a step of $30 \mathrm{deg}$. Moreover, these authors also used a polymer polarizer baked at $150^{\circ} \mathrm{C}$ as a sample with both diattenuating and birefringent properties. Chenault and Chipman ${ }^{118}$ used a rotating sample polarimeter to find linear diattenuation and retardance of the sample calculated from intensity modulation.

\subsection{Circular Retardation Phantoms}

The effect of circular birefringence is frequently associated with the presence of chiral molecules, ${ }^{119}$ such as glucose. The aggregation of the presence chiral molecules in media causes the rotation of polarization plane of linearly polarized light as it travels through that volume. Manhas et al., ${ }^{97}$ Ortega-Quijano et al., ${ }^{120}$ and Ossikovski et al. ${ }^{112}$ added glucose to a polystyrene microsphere mixture in order to induce chirality and provide optical activity properties to the phantom' (Table 5).

Malik et al. ${ }^{124}$ developed several ocular models to investigate the feasibility of measuring glucose in the eye aqueous humor with polarization-based techniques (Fig. 6). The model shown also accounts for the cornea birefringence utilizing a PMMAbased phantoms overlaying a chamber mimicking the aqueous humor. A similar approach was used by Rawer et al. ${ }^{125}$

Other intralipid suspension liquid phantoms can be made with absorbers, such as dye, and optically active molecules, such as glucose and L-lysine, to test optical activity in samples. ${ }^{18,121}$ Antonelli $^{75}$ used honey to calculate the optical activity of the sample. Pham et al. ${ }^{70}$ and Chang et al. ${ }^{18}$ studied the concentration of glucose by measuring the optical rotation angle of circular birefringence (optical activity) in human blood plasma and porcine cartilage samples. 
Table 4 Diattenuation phantoms. *Phantoms that were also tested for other polarization properties in corresponding reference paper.

\begin{tabular}{|c|c|c|c|c|c|}
\hline Diattenuation agent & Solvent/preparation & Tissue mimicking & $\begin{array}{l}\text { Phantom } \\
\text { thickness }\end{array}$ & $\begin{array}{l}\text { Transmission/ } \\
\text { reflectance }\end{array}$ & Ref. \\
\hline GNPs (nonspherical shapes) & CTAB-coated GNPs & Theoretical standard & Semi-infinite & $\mathrm{T}$ & 115 \\
\hline Kapton tape (stacked)* & Layered against a rigid base & Theoretical standard & Semi-infinite & $\mathrm{R}$ & 93 \\
\hline $\begin{array}{l}\text { Mylar (biaxially oriented } \\
\text { polyethylene terephthalate)* }\end{array}$ & Laid against a plexiglass base & Theoretical standard & Semi-infinite & $\mathrm{R}$ & 93 \\
\hline Polarizer & None & Theoretical standard & $21.59 \mathrm{~mm}$ & $\mathrm{~T}$ & 116 and 117 \\
\hline Polarizer (baked) & $150^{\circ} \mathrm{C}$ for $80 \mathrm{~min}$ & Theoretical standard & $\mathrm{N} / \mathrm{A}$ & $\mathrm{T}$ & 116 and 117 \\
\hline Polarizer (rotating) & None & Theoretical standard & $\mathrm{N} / \mathrm{A}$ & $\mathrm{T}$ & 118 \\
\hline Quarter-wave plate & None & Theoretical standard & $\mathrm{N} / \mathrm{A}$ & $\mathrm{T}$ & 116 and 117 \\
\hline Silicon (amorphous) ${ }^{\star}$ & None & Theoretical standard & Semi-infinite & $\mathrm{R}$ & 93 \\
\hline Silicon (poly-)* & None & Theoretical standard & Semi-infinite & $\mathrm{R}$ & 93 \\
\hline
\end{tabular}

Table 5 Optical activity phantoms.

\begin{tabular}{|c|c|c|c|c|c|}
\hline $\begin{array}{l}\text { Optical activity } \\
\text { agent }\end{array}$ & Solvent/preparation & Tissue mimicking & $\begin{array}{l}\text { Phantom } \\
\text { thickness }\end{array}$ & $\begin{array}{l}\text { Transmission/ } \\
\text { reflectance }\end{array}$ & Ref. \\
\hline Glucose (L-lysine) & $\begin{array}{l}\text { Distilled water, } \beta \text {-alanine, intralipid } \\
\text { suspension, trypan blue dye }\end{array}$ & Turbid biological media & Semi-infinite & $\mathrm{R}$ & 121 \\
\hline Glucose (D-) & $\begin{array}{l}\text { Water, } 2 \mu \mathrm{m} \text { polystyrene microspheres, } \\
\text { lipofundin, blood plasma, } \mathrm{SiO}_{2} \text { nanoparticles }\end{array}$ & Turbid biological media & $40 \mathrm{~mm}$ & $\mathrm{R} / \mathrm{T}$ & $\begin{array}{l}70,97,112,120 \\
122, \text { and } 123\end{array}$ \\
\hline Glucose & Water & Eye aqueous humor & Semi-infinite & $\mathrm{R}$ & $124-126$ \\
\hline Glucose & Water & Eye aqueous humor & $1 \times 1 \mathrm{~cm}^{2}$ & $\mathrm{~T}$ & 127 \\
\hline Honey & None & Turbid biological media & Semi-infinite & $\mathrm{R}$ & 75 \\
\hline Sucrose & Polyacrylamide, polystyrene microspheres & Turbid biological tissue & $1 \times 1 \times 1 \mathrm{~cm}^{3}$ & $\mathrm{~T}$ & 3 \\
\hline $\begin{array}{l}\text { L-(+) -arabinose, } \\
\text { M. racemic }\end{array}$ & Water and polystyrene microspheres & Turbid biological tissue & $1 \times 1 \times 1 \mathrm{~cm}^{3}$ & Side $T$ & 119 \\
\hline
\end{tabular}

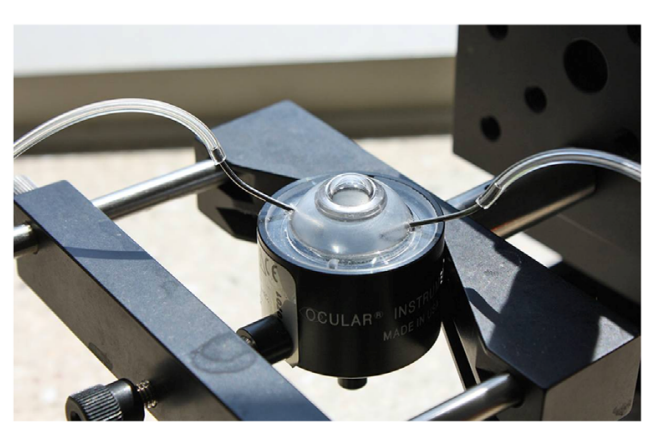

Fig. 6 Optical phantom from Ref. 124. The custom-built ocular model. Glucose concentration in the anterior section is varied through the two infusion tubes.

\section{Conclusions}

Optical phantoms that can be used for the calibration and benchmarking of polarimetric techniques and for mimicking the optical response of tissues have been used by several investigators.

It is to be noted that polarimetric optical phantoms are often unique to each research group and, aside from tests conducted on depolarization with microspheres suspensions, no standardization has been attempted. To our knowledge, only one company offers birefringent phantoms for polarized microscopy (NBS 1963A Birefringent Resolution Target by Thorlabs). As the biomedical applications of polarimetric techniques move toward quantification of directionality and retardation, more standardized phantoms are necessary. The PS-OCT phantoms proposed by Liu et al. ${ }^{108}$ are a good example of such approach. The measurements of PS-OCT's two core parameters, namely, 
retardation and azimuth of optical axis can be easily reproduced, and different instruments can be benchmarked using such standardized phantoms. These mixed properties phantoms, particularly ones that include both depolarization and retardation, are needed for many applications. Phantoms that have birefringence of form rather than just intrinsic birefringence are also needed to simulate fibrous tissues, such as the cervix, cardiac tissue, or muscle. Nevertheless, the task of creating general use phantoms is complicated by the heterogeneity of tissues, the complexity of polarized light-tissue interaction, and the strong wavelength dependence of polarization-based techniques.

For these reasons, the use of biological tissue as measurement standards is very common in polarimetric applications, but unless these samples are well-known or measured with an alternative modality (e.g., PS-OCT or second harmonic generation), the scientific rigor of these experiments remains limited.

As new fabrication modalities, such as 3-D printing and lithography, are becoming available to researchers worldwide, we believe that a collaborative effort in the development of a standardized optical phantom for polarimetry could truly benefit the scientific community.

\section{Disclosures}

The authors have no relevant financial interests in this article and no potential conflicts of interest to disclose.

\section{Acknowledgments}

We gratefully acknowledge the support of the Herbert Wertheim Foundation and NSF ERC Grant PATHS-UP EEC-1648451 and STROBE: A National Science Foundation Science and Technology Center under Grant No. DMR 1548924.

\section{References}

1. J. Vanhellemont et al., "Round robin investigation of silicon oxide on silicon reference materials for ellipsometry," Appl. Surf. Sci. 63, 45-51 (1993).

2. V. V. Tuchin, "Polarized light interaction with tissues," J. Biomed. Opt. 21(7), 071114 (2016).

3. N. Ghosh and I. A. Vitkin, "Tissue polarimetry: concepts, challenges, applications, and outlook," J. Biomed. Opt. 16(11), 110801 (2011).

4. J. Qi and D. S. Elson, "Mueller polarimetric imaging for surgical and diagnostic applications: a review," J. Biophotonics 10, 950-982 (2017).

5. J. F. de Boer, C. K. Hitzenberger, and Y. Yasuno, "Polarization sensitive optical coherence tomography: a review [Invited]," Biomed. Opt. Express 8, 1838-1873 (2017).

6. B. Baumann, "Polarization sensitive optical coherence tomography: a review of technology and applications," Appl. Sci.-Basel 7, 474 (2017).

7. B. W. Pogue and M. S. Patterson, "Review of tissue simulating phantoms for optical spectroscopy, imaging and dosimetry," J. Biomed. Opt. 11(4), 041102 (2006).

8. N. Ghosh, M. F. G. Wood, and I. A. Vitkin, "Polarimetry in turbid, birefringent, optically active media: a Monte Carlo study of Mueller matrix decomposition in the backscattering geometry," J. Appl. Phys. 105, 102023 (2009).

9. J. J. Gil and R. Ossikovski, "Polarized light and the Mueller matrix approach," Series in Optics and Optoelectronics, CRC Press, Boca Raton, Florida (2016).

10. M. R. Hee et al., "Polarization-sensitive low-coherence reflectometer for birefringence characterization and ranging," J. Opt. Soc. Am. B 9, 903-908 (1992).

11. S. Y. Lu and R. A. Chipman, "Interpretation of Mueller matrices based on polar decomposition," J. Opt. Soc. Am. A 13, 1106-1113 (1996).
12. N.-J. Jan, K. Lathrop, and I. A. Sigal, "Collagen architecture of the posterior pole: high-resolution wide field of view visualization and analysis using polarized light microscopy," Invest. Ophth. Vis. Sci. 58, 735-744 (2017).

13. Y. Lim et al., "Birefringence measurement of cornea and anterior segment by office-based polarization-sensitive optical coherence tomography," Biomed. Opt. Express 2, 2392-2402 (2011).

14. M. Wojtkowski, "High-speed optical coherence tomography: basics and applications," Appl. Opt. 49, D30-D61 (2010).

15. W. Kaminsky et al., "Simultaneous false-colour imaging of birefringence, extinction and transmittance at camera speed," J. Microsc. 228, 153-164 (2007).

16. N. Ugryumova et al., "Novel optical imaging technique to determine the 3-D orientation of collagen fibers in cartilage: variable-incidence angle polarization-sensitive optical coherence tomography," Osteoarthritis Cartilage 17, 33-42 (2009).

17. D. K. Kasaragod et al., "Experimental validation of an extended Jones matrix calculus model to study the 3-D structural orientation of the collagen fibers in articular cartilage using polarization-sensitive optical coherence tomography," Biomed. Opt. Express 3, 378-387 (2012).

18. C.-M. Chang et al., "Optical characterization of porcine articular cartilage using a polarimetry technique with differential Mueller matrix formulism," Appl. Opt. 57, 2121-2127 (2018).

19. R. Lu et al., "A polarization-sensitive light field imager for multi-channel angular spectroscopy of light scattering in biological tissues," Quant. Imaging Med. Surg. 5, 1-8 (2015).

20. R. Oldenbourg, E. D. Salmon, and P. T. Tran, "Birefringence of single and bundled microtubules," Biophys. J. 74, 645-654 (1998).

21. J. Chue-Sang et al., "Use of Mueller matrix polarimetry and optical coherence tomography in the characterization of cervical collagen anisotropy," J. Biomed. Opt. 22(8), 086010 (2017).

22. A. Pierangelo et al., "Polarimetric imaging of uterine cervix: a case study," Opt. Express 21, 14120-14130 (2013).

23. N. Agarwal et al., "Spatial evolution of depolarization in homogeneous turbid media within the differential Mueller matrix formalism," Opt. Lett. 40, 5634-5637 (2015).

24. M. R. Antonelli et al., "Mueller matrix imaging of human colon tissue for cancer diagnostics: how Monte Carlo modeling can help in the interpretation of experimental data," Opt. Express 18, 10200-10208 (2010).

25. M. R. Antonelli et al., "Impact of model parameters on Monte Carlo simulations of backscattering Mueller matrix images of colon tissue," Biomed. Opt. Express 2, 1836-1851 (2011).

26. T. Novikova et al., "Special section guest editorial: Antonello de Martino (1954-2014): in memoriam," J. Biomed. Opt. 21(7), 071101 (2016).

27. A. Pierangelo et al., "Ex-vivo characterization of human colon cancer by Mueller polarimetric imaging," Opt. Express 19, 1582-1593 (2011).

28. A. Pierangelo et al., "Ex vivo photometric and polarimetric multilayer characterization of human healthy colon by multispectral Mueller imaging," J. Biomed. Opt. 17(6), 066009 (2012).

29. A. Pierangelo et al., "Multispectral Mueller polarimetric imaging detecting residual cancer and cancer regression after neoadjuvant treatment for colorectal carcinomas," J. Biomed. Opt. 18(4), 046014 (2013).

30. J. Rehbinder et al., "Ex vivo Mueller polarimetric imaging of the uterine cervix: a first statistical evaluation," J. Biomed. Opt. 21(7), 071113 (2016).

31. S. Alali et al., "Assessment of local structural disorders of the bladder wall in partial bladder outlet obstruction using polarized light imaging," Biomed. Opt. Express 5, 621-629 (2014).

32. M. F. Wood et al., "Polarization birefringence measurements for characterizing the myocardium, including healthy, infarcted, and stem-cell-regenerated tissues," J. Biomed. Opt. 15(4), 047009 (2010).

33. W. Groner et al., "Orthogonal polarization spectral imaging: a new method for study of the microcirculation," Nat. Med. 5, 1209-1212 (1999).

34. O. Genzel-Boroviczeny et al., "Orthogonal polarization spectral imaging (OPS): a novel method to measure the microcirculation in term and preterm infants transcutaneously," Pediatr. Res. 51, 386-391 (2002).

35. S. Langer et al., "Orthogonal polarization spectral imaging versus intravital fluorescent microscopy for microvascular studies in wounds," Ann. Plast. Surg. 48, 646-653 (2002). 
36. S. Langer et al., "Orthogonal polarization spectral imaging as a tool for the assessment of hepatic microcirculation: a validation study," Transplantation 71, 1249-1256 (2001).

37. E. Uhl et al., "Intraoperative detection of early microvasospasm in patients with subarachnoid hemorrhage by using orthogonal polarization spectral imaging," Neurosurgery 52, 1307-1317; discussion 1315-1307 (2003).

38. E. von Dobschuetz et al., "Noninvasive in vivo assessment of the pancreatic microcirculation: orthogonal polarization spectral imaging," Pancreas 26, 139-143 (2003).

39. R. R. Anderson, "Polarized light examination and photography of the skin," Arch. Dermatol. 127, 1000-1005 (1991).

40. S. L. Jacques, J. R. Roman, and K. Lee, "Imaging superficial tissues with polarized light," Lasers Surg. Med. 26, 119-129 (2000).

41. S. L. Jacques, J. C. Ramella-Roman, and K. Lee, "Imaging skin pathology with polarized light," J. Biomed. Opt. 7(3), 329-340 (2002).

42. S. P. Morgan et al., "Rotating orthogonal polarization imaging," Opt. Lett. 33, 1503-1505 (2008).

43. J. C. Ramella-Roman et al., "Design, testing, and clinical studies of a handheld polarized light camera," J. Biomed. Opt. 9(6), 13051310 (2004).

44. P. Ghassemi et al., "Out-of-plane Stokes imaging polarimeter for early skin cancer diagnosis," J. Biomed. Opt. 17(7), 076014 (2012).

45. P. Ghassemi et al., "A new approach for optical assessment of directional anisotropy in turbid media," J. Biophotonics 9, 100-108 (2016).

46. P. Ghassemi et al., "A polarized multispectral imaging system for quantitative assessment of hypertrophic scars," Biomed. Opt. Express 5, 3337-3354 (2014).

47. M. Bonesi et al., "High-speed polarization sensitive optical coherence tomography scan engine based on Fourier domain mode locked laser," Biomed. Opt. Express 3, 2987-3000 (2012).

48. S. Sakai et al., "In vivo evaluation of human skin anisotropy by polarization-sensitive optical coherence tomography," Biomed. Opt. Express 2, 2623-2631 (2011).

49. J. Qi and D. S. Elson, "A high definition Mueller polarimetric endoscope for tissue characterization," Sci. Rep. 6, 25953 (2016).

50. S. Alali et al., "Quantitative correlation between light depolarization and transport albedo of various porcine tissues," J. Biomed. Opt. 17(4), 045004 (2012).

51. K. A. Montejo et al., Vol. 10043, pp. 1004303-1004310 (2017).

52. A. H. Hielscher and S. Bartel, "Diffuse backscattering Mueller matrix analysis for tissue diagnostics with polarized light," Proc. SPIE 3917, 43-53 (2000).

53. A. H. Hielscher, J. R. Mourant, and I. J. Bigio, "Influence of particle size and concentration on the diffuse backscattering of polarized light from tissue phantoms and biological cell suspensions," Appl. Opt. 36, 125-135 (1997).

54. M. Sun et al., "Characterizing the microstructures of biological tissues using Mueller matrix and transformed polarization parameters," Biomed. Opt. Express 5, 4223-4234 (2014).

55. M. A. Wallenburg et al., "Comparison of optical polarimetry and diffusion tensor MR imaging for assessing myocardial anisotropy," J. Innovative Opt. Health Sci. 3, 109-121 (2010).

56. M. F. G. Wood et al., "Effects of formalin fixation on tissue optical polarization properties," Phys. Med. Biol. 56, N115 (2011).

57. N. Ghosh et al., "Mueller matrix decomposition for polarized light assessment of biological tissues," J. Biophotonics 2, 145-156 (2009).

58. B. Yang et al., "Polarized light spatial frequency domain imaging for non-destructive quantification of soft tissue fibrous structures," Biomed. Opt. Express 6, 1520-1533 (2015).

59. J. Chue-Sang et al., "Use of combined polarization-sensitive optical coherence tomography and Mueller matrix imaging for the polarimetric characterization of excised biological tissue," J. Biomed. Opt. 21(7), 071109 (2016).

60. W. Goth et al., 9710, 971018-971019 (2016).

61. S. Sugita and T. Matsumoto, "Quantitative measurement of the distribution and alignment of collagen fibers in unfixed aortic tissues," J. Biomech. 46, 1403-1407 (2013).

62. C. Fan and G. Yao, "Imaging myocardial fiber orientation using polarization sensitive optical coherence tomography," Biomed. Opt. Express 4, 460-465 (2013).
63. Y. Gan and C. P. Fleming, "Extracting three-dimensional orientation and tractography of myofibers using optical coherence tomography," Biomed. Opt. Express 4, 2150-2165 (2013).

64. C. P. Fleming et al., "Quantification of cardiac fiber orientation using optical coherence tomography," J. Biomed. Opt. 13(3), 030505 (2008).

65. B. Baumann et al., "Polarization sensitive optical coherence tomography of melanin provides intrinsic contrast based on depolarization," Biomed. Opt. Express 3, 1670-1683 (2012).

66. C. He et al., "Characterizing microstructures of cancerous tissues using multispectral transformed Mueller matrix polarization parameters," Biomed. Opt. Express 6, 2934-2945 (2015).

67. M. Yamanari, S. Makita, and Y. Yasuno, "Polarization-sensitive sweptsource optical coherence tomography with continuous source polarization modulation," Opt. Express 16, 5892-5906 (2008).

68. X. Li, J. C. Ranasinghesagara, and G. Yao, "Polarization-sensitive reflectance imaging in skeletal muscle," Opt. Express 16, 9927-9935 (2008).

69. S. Sridhar and A. Da Silva, "Enhanced contrast and depth resolution in polarization imaging using elliptically polarized light," J. Biomed. Opt. 21(7), 071107 (2016).

70. H. T. T. Pham et al., "Optical parameters of human blood plasma, collagen, and calfskin based on the Stokes-Mueller technique," Appl. Opt. 57, 4353-4359 (2018).

71. H. R. Lee et al., SPIE Photonics Europe, Vol. 10677, pp. 8 (2018).

72. P. J. Wu and J. T. Walsh, "Stokes polarimetry imaging of rat-tail tissue in a turbid medium using incident circularly polarized light," Lasers Surg. Med. 37, 396-406 (2005).

73. M. Todorović et al., "Determination of local polarization properties of biological samples in the presence of diattenuation by use of Mueller optical coherence tomography," Opt. Lett. 29, 2402-2404 (2004).

74. L. X. Chin et al., "En face parametric imaging of tissue birefringence using polarization-sensitive optical coherence tomography," $J$. Biomed. Opt. 18(6), 066005 (2013).

75. M. R. Antonelli, "Biomedical applications of polarimetric imaging contrast. Initial studies for scattering media and human tissues," Thesis, Ecole Polytechnique, France (2011).

76. C. Fan and G. Yao, "Mapping local retardance in birefringent samples using polarization sensitive optical coherence tomography," Opt. Lett. 37, 1415-1417 (2012).

77. S. Bancelin et al., "Determination of collagen fiber orientation in histological slides using Mueller microscopy and validation by second harmonic generation imaging," Opt. Express 22, 22561-22574 (2014).

78. J. Chue-Sang et al., "Use of Mueller matrix colposcopy in the characterization of cervical collagen anisotropy," J. Biomed. Opt. 23(12), 121605 (2018).

79. E. M. Spiesz, W. Kaminsky, and P. K. Zysset, "A quantitative collagen fibers orientation assessment using birefringence measurements: calibration and application to human osteons," J. Struct. Biol. 176, 302-306 (2011).

80. S. Jiao and L. V. Wang, "Two-dimensional depth-resolved Mueller matrix of biological tissue measured with double-beam polarizationsensitive optical coherence tomography," Opt. Lett. 27, 101-103 (2002).

81. S. Jiao et al., "Fiber-based polarization-sensitive Mueller matrix optical coherence tomography with continuous source polarization modulation," Appl. Opt. 44, 5463-5467 (2005).

82. Z. Lu, D. Kasaragod, and S. J. Matcher, "Conical scan polarizationsensitive optical coherence tomography," Biomed. Opt. Express 5, 752-762 (2014).

83. Z. Lu, D. K. Kasaragod, and S. J. Matcher, "Optic axis determination by fibre-based polarization-sensitive swept-source optical coherence tomography," Phys. Med. Biol. 56, 1105-1122 (2011).

84. R. Ossikovski, "Differential matrix formalism for depolarizing anisotropic media," Opt. Lett. 36, 2330-2332 (2011).

85. J. M. Schmitt, A. H. Gandjbakhche, and R. F. Bonner, "Use of polarized-light to discriminate short-path photons in a multiply scattering medium," Appl. Opt. 31, 6535-6546 (1992).

86. S. Rehn et al., "Depth probing of diffuse tissues controlled with elliptically polarized light," J. Biomed. Opt. 18(1), 016007 (2013).

87. J. C. Ramella-Roman, S. A. Prahl, and S. L. Jacques, "Three Monte Carlo programs of polarized light transport into scattering media: part II," Opt. Express 13, 10392-10405 (2005). 
88. T. Yun et al., "Monte Carlo simulation of polarized photon scattering in anisotropic media," Opt. Express 17, 16590-16602 (2009).

89. F. C. Mackintosh et al., "Polarization memory of multiply scatteredlight: reply," Phys. Rev. B 45, 8165-8165 (1992).

90. M. K. Swami et al., "Effect of gold nanoparticles on depolarization characteristics of intralipid tissue phantom," Opt. Lett. 38, 28552857 (2013).

91. B. Kunnen et al., "Application of circularly polarized light for noninvasive diagnosis of cancerous tissues and turbid tissue-like scattering media," J. Biophoton. 8, 317-323 (2015).

92. M. Ahmad et al., "Do different turbid media with matched bulk optical properties also exhibit similar polarization properties?" Biomed. Opt. Express 2, 3248-3258 (2011).

93. J. C. Petermann, University of Akron (2012).

94. M. J. Rakovic et al., "Light backscattering polarization patterns from turbid media: theory and experiment," Appl. Opt. 38, 3399-3408 (1999).

95. D. Cote and I. Vitkin, "Robust concentration determination of optically active molecules in turbid media with validated three-dimensional polarization sensitive Monte Carlo calculations," Opt. Express 13, 148-163 (2005).

96. N. Ghosh et al., "Depolarization of light in tissue phantoms: effect of collection geometry," Opt. Commun. 222, 93-100 (2003).

97. S. Manhas et al., "Mueller matrix approach for determination of optical rotation in chiral turbid media in backscattering geometry," Opt. Express 14, 190-202 (2006).

98. Y. Guo et al., "A study on forward scattering Mueller matrix decomposition in anisotropic medium," Opt. Express 21, 18361-18370 (2013).

99. H. He et al., "Two-dimensional backscattering Mueller matrix of sphere-cylinder scattering medium," Opt. Lett. 35, 2323-2325 (2010).

100. B. Laude-Boulesteix et al., "Mueller polarimetric imaging system with liquid crystals," Appl. Opt. 43, 2824-2832 (2004).

101. E. Garcia-Caurel et al., "Application of spectroscopic ellipsometry and Mueller ellipsometry to optical characterization," Appl. Spectrosc. 67, 1-21 (2013).

102. M. S. Wróbel et al., SPIE, Vol. 20, pp. 10 (2015).

103. M. S. Wróbel et al., "Multi-layered tissue head phantoms for noninvasive optical diagnostics," J. Innovative Opt. Health Sci. 8, 1541005 (2015).

104. A. A. Hamza et al., "Determination of the intrinsic birefringence of polymeric fibres," Polymer Testing 23, 203-208 (2004).

105. N. Ghosh, M. F. Wood, and I. A. Vitkin, "Mueller matrix decomposition for extraction of individual polarization parameters from complex turbid media exhibiting multiple scattering, optical activity, and linear birefringence," J. Biomed. Opt. 13(4), 044036 (2008).

106. P. W. Gibson, H. L. Schreuder-Gibson, and D. Rivin, "Electrospun fiber mats: transport properties," AIChE J. 45, 190-195 (1999).

107. Y. Wang et al., "Study on the validity of $3 \times 3$ Mueller matrix decomposition," J. Biomed. Opt. 20(6), 065003 (2015).

108. X. Liu et al., "Tissue-like phantoms for quantitative birefringence imaging," Biomed. Opt. Express 8, 4454-4465 (2017).

109. S. Alali, A. Gribble, and I. A. Vitkin, "Rapid wide-field Mueller matrix polarimetry imaging based on four photoelastic modulators with no moving parts," Opt. Lett. 41, 1038-1041 (2016).

110. B. Heise et al., Spatially resolved stress measurements in materials with polarisation-sensitive optical coherence tomography: image acquisition and processing aspects," Strain 46, 61-68 (2010).
111. M. A. Wallenburg et al., "Polarimetry-based method to extract geometry-independent metrics of tissue anisotropy," Opt. Lett. 35(15), 2570-2572 (2010).

112. R. Ossikovski, "Analysis of depolarizing Mueller matrices through a symmetric decomposition," J. Opt. Soc. Am. A 26, 1109-1118 (2009).

113. D. Stifter et al., "Spectral domain polarization sensitive optical coherence tomography at $1.55 \mu \mathrm{m}$ : novel developments and applications for dynamic studies in materials science," Proc. SPIE 7889, $78890 \mathrm{Z}$ (2011).

114. M. F. Wood, X. Guo, and I. A. Vitkin, "Polarized light propagation in multiply scattering media exhibiting both linear birefringence and optical activity: Monte Carlo model and experimental methodology," J. Biomed. Opt. 12(1), 014029 (2007).

115. M. K. Swami et al., "Spectral Mueller matrix measurements for characterization of depolarization from non-spherical gold nanoparticles," Opt. Commun. 308, 136-141 (2013).

116. P.-C. Chen et al., "Measurement of linear birefringence and diattenuation properties of optical samples using polarimeter and Stokes parameters," Opt. Express 17, 15860-15884 (2009).

117. L. Yu Lung et al., "Using polarimeter and Stokes parameters for measuring linear birefringence and diattenuation properties of optical samples," in EPJ Web of Conf. 6, 32001 (2010).

118. D. B. Chenault and R. A. Chipman, "Measurements of linear diattenuation and linear retardance spectra with a rotating sample spectropolarimeter," Appl. Opt. 32, 3513-3519 (1993).

119. K. C. Hadley and I. A. Vitkin, "Optical rotation and linear and circular depolarization rates in diffusively scattered light from chiral, racemic, and achiral turbid media," J. Biomed. Opt. 7(3), 291-299 (2002).

120. N. Ortega-Quijano et al., "Comparative study of optical activity in chiral biological media by polar decomposition and differential Mueller matrices analysis," Proc. SPIE 7906, 790612 (2011).

121. M. Mehrubeoglu et al., "Effect of molecular concentrations in tissuesimulating phantoms on images obtained using diffuse reflectance polarimetry," Opt. Express 3, 286-298 (1998).

122. T. L. Chen et al., "Noninvasive measurement of glucose concentration on human fingertip by optical coherence tomography," J. Biomed. Opt. 23(4), 047001 (2018).

123. Q. H. Phan and Y. L. Lo, "Stokes-Mueller matrix polarimetry system for glucose sensing," Opt. Laser Eng. 92, 120-128 (2017).

124. B. H. Malik, C. W. Pirnstill, and G. L. Cote, "Dual-wavelength polarimetric glucose sensing in the presence of birefringence and motion artifact using anterior chamber of the eye phantoms," J. Biomed. Opt. 18(01), 017007 (2013).

125. R. Rawer, W. Stork, and C. F. Kreiner, "Non-invasive polarimetric measurement of glucose concentration in the anterior chamber of the eye," Graefes Arch. Clin. Exp. Ophthalmol. 242, 1017-1023 (2004).

126. R. R. Ansari, S. Bockle, and L. Rovati, "New optical scheme for a polarimetric-based glucose sensor," J. Biomed. Opt. 9(1), 103-115 (2004).

127. Z. F. Yu, C. W. Pirnstill, and G. L. Cote, "Dual-modulation, dual-wavelength, optical polarimetry system for glucose monitoring," J. Biomed. Opt. 21(8), 087001 (2016).

Biographies of the authors are not available. 